\title{
A EDUCAÇÃO DA CRIANÇA E O DESENVOLVIMENTO DOS CONCEITOS CIENTÍFICOS FRENTE À FORMAÇÃO (DES) HUMANA NA SOCIEDADE DE CLASSES
}

\author{
Eliane Brunetto Pertile ${ }^{1}$ \\ Nerli Nonato Ribeiro Mori ${ }^{2}$
}

\section{RESUMO}

O texto aqui apresentado tem como objetivo analisar as contribuições de Vigotski para a compreensão do desenvolvimento dos conceitos científicos na criança em idade escolar. Assim, partimos da seguinte questão: quais as contribuições que a compreensão do desenvolvimento dos conceitos científicos pode trazer para discutirmos a formação proporcionada por meio da atual organização escolar? Para tanto, realizamos uma pesquisa bibliográfica fundamentada principalmente nas produções de Vigotski. Destacamos, dentre os vários subsídios para o campo educacional, que os conceitos científicos possibilitam a ação consciente frente à realidade e se desenvolvem por processos mediados. Entendemos que essas contribuições podem se constituir como premissas orientadoras para o ensino à medida que seja adotada uma perspectiva de formação condizente com a expectativa de humanização dos sujeitos. Constatamos também que a educação instituída na atualidade, sob a organização do trabalho na sociedade de classes, tem significativos limites para uma formação que possibilite o desenvolvimento dos conceitos científicos.

Palavras-chave: Teoria Histórico-Cultural; educação escolar; desenvolvimento humano; contradições sociais.

\section{THE EDUCATION OF THE CHILD AND THE DEVELOPMENT OF SCIENTIFIC CONCEPTS IN RELATION TO TRAINING (DES) HUMAN IN CLASS SOCIETY}

\begin{abstract}
The text presented intended to analyze the contributions of Vigotski to understanding the development of scientific concepts in children of school age. So we start with the following question: what are the contributions that the understanding of the development of scientific concepts can bring to discuss the training provided by the current school organization? To so much, we conducted a literature search based mainly in Vigotski productions. We highlight, among the various subsidies for the educational field, that the scientific concepts they can enable conscious a action in front the reality and they develop by mediated processes. We understand that these contributions can guiding the teaching the extent that is either adopted a combined teaching approach with the expectation of humanizing the person. We also note that education established today in the organization of work in class society has its limits for a training that enable the development of scientific concepts.
\end{abstract}

Keywords: Theory Historical-Cultural; schooling; human development; social contradictions. 


\section{Introdução}

O presente artigo centra-se na intenção de reconhecer as contribuições que a Teoria Histórico-Cultural traz para o campo da educação por meio do estudo do desenvolvimento dos conceitos científicos na infância. Nesse sentido, destacamos o trabalho no espaço escolar como possibilidade de promover o desenvolvimento das formas mais elaboradas de pensamento, o que se torna critério para a formação da consciência frente à realidade e para que o sujeito amplie sua capacidade de compreensão passando das questões mais simples às mais complexas que se apresentam no cotidiano e nas relações que determinam a vida em sociedade.

Vigotski apresentou significativas formulações acerca do processo pelo qual a criança passa dos conceitos espontâneos aos conceitos científicos. Essas elaborações compostas no arcabouço da Teoria Histórico-Cultural apresentam grande relevância para epistemologia da educação por permitir a reflexão acerca do significado e do papel do ensino na promoção da aprendizagem e, consequentemente, no desenvolvimento da criança em idade escolar.

O desenvolvimento de pesquisas experimentais acerca dessa questão por Vigotski foi motivado pela percepção de que em sua época havia poucas pesquisas que se encarregavam de discutir a formação dos conceitos científicos, sendo que a maioria das investigações se detinha apenas aos conceitos formulados espontaneamente e transportavam as constatações obtidas acerca desses para a compreensão dos conceitos mais complexos. Por tal situação, as elaborações existentes eram inconsistentes e não davam respaldo para compreender a questão da aprendizagem (VIGOTSKI, 2009).

A razão que nos faz buscar as elaborações do autor sobre os conceitos científicos na atualidade está no fato de percebermos que existem muitas variações de posicionamentos teóricos e diversas elaborações acerca do trabalho escolar que apontam para rumos divergentes entre si, enfatizando com frequência o abandono ou a secundarização de uma ação docente intencional e direcionada para o ensino dos conteúdos formais que dão suporte aos conceitos científicos.

O estudo de Vigotski sobre o desenvolvimento do pensamento encontra-se ligado às questões da aprendizagem, o que permite refletir sobre o trabalho educacional, tendo em vista que partimos da compreensão de que o ensino e a aprendizagem são processos interligados.

Consideramos que a pesquisa de Vigotski apresenta considerações cuja valia perdura até a atualidade e permite a discussão acerca da atividade escolar e do significado da mediação no desenvolvimento da capacidade psíquica da criança. Assim, a questão do desenvolvimento dos conceitos científicos se constituiu numa contribuição da psicologia para a educação por possibilitar a compreensão das leis do desenvolvimento humano como forma de melhor orientar o processo educativo.

Portanto, a compreensão do processo pelo qual ocorre a tomada de consciência em níveis mais elevados é substancial diante da intenção de refletir acerca das atividades escolares. $\mathrm{O}$ estudo acerca da capacidade de desenvolver conceitos científicos possibilita a compreensão mais profunda dos processos de constituição do psiquismo humano, o que oportuniza discutir a adequação e a especificidade do trabalho educacional. 


\section{O Materialismo Histórico-Dialético como base fundante da Teoria Histórico-Cultural}

A compreensão do processo de formação dos conceitos científicos como aspecto decisivo na constituição das capacidades psicológicas humanas e a perspectiva de contribuição desse conhecimento para o campo educacional nos indicam a necessidade de buscar aprofundamento nos pressupostos da Teoria Histórico-Cultural, uma vez que este referencial apresenta estudos que foram inaugurais em relação a questão do pensamento científico, bem como fornece elementos que permitem debater a educação em suas problemáticas atuais.

A Teoria Histórico-Cultural, constituída a partir dos estudos de Lev SemenovitchVigotski, tem seus fundamentos no Materialismo Histórico-Dialético. Assim, compreende o sujeito em sua constituição humana como resultado de um processo histórico, o que significa que as capacidades desenvolvidas não se restringem as questões relativas à individualidade ou aos aspectos biológicos/naturais, mas são definidas pelas condições obtidas a partir de relações coletivas. Vigotski não desconsidera os aspectos biológicos na constituição do sujeito, tanto que em "Fundamentos de Defectologia" (1989) desenvolveu pesquisas significativas com crianças cujo desenvolvimento apresentava especificidades decorrentes de algum "defeito" orgânico, mas suas premissas sempre reafirmaram o caráter superior dos determinantes sociais sobre as questões naturais.

A compreensão presente na Teoria Histórico-Cultural de que o sujeito obtém suas capacidades psicológicas a partir das apropriações culturais deriva da concepção de homem estabelecida a partir dos pressupostos do Materialismo Histórico-Dialético, como constituído por meio das relações sociais.

Dessa forma, o Materialismo Histórico-Dialético, de Karl Marx e Friedrich Engels, e a Teoria Histórico-Cultural, fundada por Lev SemenovitchVigotski, nos fornecem elementos que viabilizam a discussão sobre a pertinência das atividades escolares frente ao objetivo de promover o crescimento contínuo dos níveis mais elevados de consciência, uma vez que compreende os processos psíquicos são obtidos pela relação com os outros homens, pelas mediações. Pois, os autores desse quadro teórico permitem entender a educação como parte das relações sociais que compõe a individualidade de cada sujeito e as capacidades psicológicas eminentemente humanas.

O Materialismo Histórico-Dialético, enquanto método de apreensão da realidade, contribui para a compreensão da criança como sujeito histórico, cuja individualidade se constitui a partir das relações coletivas predominantes em dado momento. Portanto, compreende-se que são as relações sociais que constituem o sujeito proporcionando-lhe ou não a superação de sua condição natural e espontânea pelas formas de comportamento humano mais desenvolvidas e complexas.

As formulações obtidas por Vigotski foram condizentes com o projeto de formação humana que se configurou na Rússia após a Revolução de 1917. Assim, não se tratava de um estudo acerca das atividades educacionais de forma isolada, mas de uma nova perspectiva de organização social em que os homens deviam ser formados para a coletividade, para o bem comum. Portanto, discutia-se a busca por uma educação, condizente com uma perspectiva de contexto social, que proporcionasse um desenvolvimento amplo de todos os aspectos possíveis em cada sujeito.

Consideramos, portanto, que não é possível operar uma aplicação imediata da teoria de Vigotski em nossa realidade educacional, tendo em vista a disparidade entre o contexto econômico, social e político que vivemos e aquele de origem das elaborações do autor. Os limites que determinam a formação humana em nossa sociedade configuram-se como restrições para a aplicação dos pressupostos da teoria Histórico-Cultural. Mas, entendemos 
que mesmo dentro de tais condições, as formulações obtidas nas pesquisas desenvolvidas por Vigotski, além de esclarecer acerca da constituição das capacidades mentais humanas, podem apontar orientações e ser problematizadoras da realidade educacional que vivemos.

\section{Os conceitos espontâneos e os conceitos científicos}

Vigotski dedicou-se ao estudo do desenvolvimento dos conceitos científicos na idade escolar por entender que esta é a atividade predominante para a promoção do desenvolvimento neste período. Assim, compreende que a forma pela qual a criança passa dos conhecimentos espontâneos aos científicos é um fator primordial para a organização do ensino.

Para o autor as leis que orientam a formulação dos conceitos científicos contém a chave de toda a história do desenvolvimento mental da criança e precisa ser o ponto de partida para o estudo do desenvolvimento infantil. Dessa forma, o objeto do estudo da infância na escola "[...] é o desenvolvimento da criança, particularmente o seu desenvolvimento mental, que se realiza em função da aprendizagem, da atividade" (VIGOTSKI, 2010, p. 517).

A relação estabelecida entre os conceitos espontâneos e científicos no pensamento da criança é questão decisiva para refletir acerca do trabalho escolar. Tem-se que o desenvolvimento dos conceitos se inicia antes do ingresso na escola. Mas, sabemos igualmente que o início da escolarização "significa um caminho interessantíssimo e novo no desenvolvimento dos conceitos" (VIGOTSKI, 2010, p. 524).

Ao estudar a relação entre o desenvolvimento dos conceitos espontâneos e os conceitos não-espontâneos, Vigotski $(2009,2010)$ supera as perspectivas de sua época em que predominava os entendimentos de que os conceitos científicos são aprendidos de forma pronta ou que não diferem do desenvolvimento dos conceitos espontâneos.

A partir de Vigotski, entende-se que os conceitos são desenvolvidos, pois a princípio as generalizações que a criança estabelece são mais incipientes, o que se modifica gradativamente. Quando uma palavra nova, ligada a um determinado significado, é aprendida pela criança o seu significado ainda não está de todo apreendido. No início, temse uma generalização mais elementar, que é substituída por generalizações de um tipo cada vez mais elevado, culminando na formação de verdadeiros conceitos (VIGOTSKI, 2010, p. 104).

Assim, "o caminho entre o primeiro momento em que a criança estabelece contato com o novo conceito e o momento em que a palavra e o conceito se tornam propriedade da criança é um complexo processo psicológico interior [...]" (VIGOTSKI, 2009, p. 250) que não se consolida de forma espontânea, mas para além da espontaneidade, pois exige mediações, intencionalidade e metas previamente estabelecidas.

O ensino consciente de novos conceitos e formas da palavra ao aluno não só é possível como pode ser fonte de um desenvolvimento superior dos conceitos. Neste sentido, $\mathrm{o}$ ato de ensinar tem significado preponderante no desenvolvimento dos conceitos nãoespontâneos.

Este entendimento se configura num marco significativo para refletir acerca das questões educacionais, pois frente à organização do ensino, nos propõe a superação de perspectivas que se fundamentam na espontaneidade como forma de compreensão do desenvolvimento humano.

Outra contribuição para o campo educacional se dá a partir da relação que Vigotski reconhece entre aprendizagem e desenvolvimento, pois entende que o desenvolvimento da criança "tem sua lógica interna, vinculada, mas não dissolvida na dinâmica da aprendizagem 
escolar" (VIGOTSKI, 2010). Nesse sentido, a aprendizagem escolar promove o desenvolvimento infantil. Logo: os conceitos científicos dependem do ensino, e este se coloca para a efetivação da aprendizagem que, por sua vez, é a força propulsora do desenvolvimento humano.

Os conceitos científicos não se desenvolvem exatamente como os espontâneos e não repetem as vias do desenvolvimento dos conceitos espontâneos. São processos intimamente interligados, mas específicos, capazes de exercer influências um sobre o outro.

Os conceitos científicos revelam traços opostos e traços afins àqueles que conhecemos da investigação dos conceitos espontâneos. O limite entre ambos os conceitos é sumamente fluído e no curso real do desenvolvimento pode passar infinitas vezes para ambos os lados. Conforme argumenta Vigotski,

[...] o acúmulo de conhecimentos leva invariavelmente ao aumento dos tipos de pensamento científico, o que por sua vez, se manifesta no desenvolvimento do pensamento espontâneo e redunda na tese do papel prevalente da aprendizagem no desenvolvimento do aluno escolar (VIGOTSKI, 2009, p.243).

Ou seja, embora distintos entre si, os conceitos espontâneos e os não-espontâneos se influenciam mutuamente. $\mathrm{O}$ desenvolvimento dos primeiros é condição substancial para o desencadeamento de novas formas de pensar que estão vinculadas aos conhecimentos os científicos. Consequentemente, um novo patamar de apropriação dos conhecimentos científicos reconfigura as possibilidade estabelecidas no âmbito dos conceitos espontâneos. De acordo, com Vigotski (1991):

[...] os rudimentos de sistematização primeiro entram na mente da criança, por meio do seu contato com os conceitos científicos, e são depois transferidos para os conceitos cotidianos, mudando a sua estrutura psicológica de cima para baixo (p. 80).

Constata-se, portanto, que quanto mais é ampliada a capacidade de elaboração mental por meio dos conceitos científicos, tanto mais eficiente é a forma como o sujeito lida com os elementos de sua cotidianidade. Dessa perspectiva, não é pelo pensamento simplificado que se entende o próprio cotidiano, mas pelas formas mais elaboradas de pensamento, uma vez que estas tornam possível a tomada de consciência da realidade. Pois, "no campo dos conceitos científicos, ocorrem níveis mais elevados de tomada de consciência do que nos conceitos espontâneos" (VIGOTSKI, 2009, p.243).

O pensamento abstrato, proveniente do desenvolvimento dos conceitos científicos, constitui "[...] a mediação que possibilita passar de um nível de concretude a outro" (MEKSENAS, 1992, p. 94). Ou seja, a realidade, que em sua concretude imediata apresentase desorganizada e indecifrável, passa a ser percebida pela consciência, mediada pelo pensamento abstrato e compreendida em sua multiplicidade de relações.

O desenvolvimento dos conceitos científicos só é possível depois que os conceitos espontâneos atingiram um nível próprio da idade escolar, assim os primeiros se apoiam no percurso já obtido pelos conceitos próprios do cotidiano. Entretanto, os conceitos científicos não podem ficar limitados as demandas da espontaneidade, pois quando, por meio do ensino, "há os momentos programáticos no processo educacional, o desenvolvimento dos conceitos científicos supera o desenvolvimento dos espontâneos" (VIGOTSKI, 2009, p. 243).

Por outro lado, como vimos, há também um movimento de retorno, que se caracteriza de forma descendente (VIGOTSKI, 2009), pois o desenvolvimento dos conceitos científicos 
não pode deixar de influenciar o nível dos conceitos espontâneos anteriormente construídos. Assim, as apropriações científicas têm o poder de mudar a forma como o sujeito se relaciona com o mundo, em seu cotidiano.

Trata-se de um processo único de formação de conceitos, mas estes têm entre si uma diferença substancial para pensarmos o ensino escolar: a exigência da mediação para o desenvolvimento dos conceitos científicos.

Enquanto os conceitos espontâneos se constituem pela relação do sujeito com a realidade, pela própria atividade vital, os conceitos científicos exigem formas organizadas de mediação, previamente estabelecidas e didaticamente pensadas. O aprendizado é uma das principais fontes de conceitos da criança em idade escolar e também uma poderosa força que direciona o seu desenvolvimento, determinando o destino de todo o seu desenvolvimento mental.

A mente se defronta com os problemas de forma diferente quando assimila os conceitos na escola em relação a quando é entregue aos seus próprios recursos. A consciência reflexiva chega à criança através dos portais dos conhecimentos científicos (VIGOTSKI, 2009). Assim, quando transmitimos à criança um conhecimento sistemático, ensinamos-lhe muitas coisas que ela não pode ver ou vivenciar diretamente.

Por meio do ensino a criança passa dos conceitos espontâneos aos não-espontâneos. O pensamento infantil supera a condição de ser não deliberado e inconsciente de si próprio e obtém a percepção consciente das relações. Ou seja, a tomada de consciência exige um processo intencional e arbitrário: mediado pelo ensino.

Nesse sentido, as formas de organização do ensino e principalmente a viabilização de maneiras de proceder metodologicamente para proporcionar de modo mais eficaz a passagem dos conceitos espontâneos aos conceitos científicos parece-nos uma preocupação que precisa ser assumida pela educação.

Essas constatações nos permitem formular discussões preciosas para a educação escolar, principalmente em nossos dias, marcados pela égide da sociedade de classes, em que a tendência predominante é de uma formação unilateral e limitada, restrita às questões mais elementares do cotidiano.

Compreendemos que diante da intenção de obter uma educação para a humanização, é preciso colocar em cheque as formas educacionais que prescindem ou secundarizam o ensino e o trabalho com os conhecimentos científicos. Dedicamo-nos assim, na sequência desse trabalho, a compreender os fundamentos dos aspectos educacionais que são condizentes com o atual estágio de organização do processo produtivo estabelecido sob a forma da propriedade privada.

\section{A formação humana diante dos determinantes materiais da sociedade de classes}

$\mathrm{Na}$ atualidade não é difícil verificar a problemática que envolve a educação escolar, tendo em vista que é corrente a informação de que os alunos chegam aos níveis mais elevados de ensino sem a apropriação dos conteúdos mínimos estabelecidos para aquela faixa de escolarização. Assim, nota-se que o acesso à escola tem sido, de modo geral, garantido, mas o acesso aos conhecimentos não está sendo assegurado. Nesse sentido, indagamo-nos porque a educação não está cumprindo sua função? Ou estaria cumprindo uma tarefa diferente daquela por nós esperada?

A educação escolar, como parte do conjunto de relações sociais, encontra-se em meio a uma realidade marcada temporalmente e o significado que tem na formação da individualidade de cada pessoa varia de acordo com a forma de produção da existência instituída coletivamente, uma vez que é a materialidade da vida que define o homem 
almejado e, por consequência, a formação pretendida. Por isso dedicamo-nos a debater a questão da organização do trabalho na sociedade vigente como possibilidade de elucidar a problemática que envolve os fins da escola na atualidade, tendo em vista a busca por uma organização do trabalho educacional que possibilite o desenvolvimento dos conceitos científicos.

Karl Marx se preocupou em estudar a sociedade capitalista compreendendo sua constituição e desenvolvimento. Dentre as constatações obtidas, o autor evidenciou que a organização social baseada na divisão de classes e sob a égide da burguesia se sustenta por meio da exploração do trabalho associada à divisão desigual dos bens produzidos. Essa é uma das características essências desse modo de produção e marca a materialidade que é determinante da organização e dos fins da educação e da formação da individualidade dos sujeitos.

Compreende-se que a educação tem seus fins estabelecidos pelas relações de trabalho que são predominantes. Portanto, o processo educativo é influenciado pelos propósitos hegemônicos nesta organização social. Nesse sentido, compreender as finalidades pelas quais a educação é encaminhada exige considerar o papel fundamental que o trabalho ass ume na constituição humana e em relação às demais questões que emergem nesta sociedade.

O trabalho, entendido a partir dos autores que se fundamentam no Materialismo Histórico-Dialético, é atividade humana por excelência e constitutiva das características que diferenciam o homem dos outros animais.

De acordo com Leontiev (1978), por meio da educação desenvolvida diretamente na atividade laboral o homem obteve ao longo da história a composição das características humanas mais fundamentais, a própria organização anatômica do homem se modificou, alterou-se substancialmente compondo a espécie humana. Assim, a organização dos homens pelo trabalho foi condição primeira e fundamental da existência humana, acarretou a transformação e a humanização do cérebro, dos órgãos de atividade externa e dos órgãos do sentido (LEONTIEV, 1978, p. 70).

Portanto, o trabalho, em sua constituição histórica, tem em si um princípio educativo e foi propulsor da transformação da capacidade intelectiva humana desde os períodos mais primitivos, bem como é indispensável para a projeção da consciência humana quando a sociedade atinge níveis mais elevados de elaboração.

Portanto, a gênese da consciência humana está nas atividades de trabalho, no domínio do homem sobre a natureza por meio das ações coletivas. Por isso, a organização da vida em sociedade e a apropriação e o aperfeiçoamento dos instrumentos pelo incremento das forças produtivas define, em diferentes períodos, o desenvolvimento da psique humana (LEONTIEV, 1978).

Ocorre, no entanto, que, na atual sociedade, a mais avançada forma de organização do processo produtivo já obtida convive com as mais aviltantes formas de alienação humana. Essa é uma contradição que confere ao trabalho o caráter ambíguo de produzir o homem e destruí-lo, sendo esse um processo que marca a consciência e o desenvolvimento de cada sujeito.

A organização do trabalho na sociedade capitalista se encontra permeada de contradições que marcam de forma destrutiva o ser humano. Pois, o atual patamar de desenvolvimento das forças produtivas, capaz de obter resultados nunca antes esperados e com uma redução de tempo surpreendente, confere ao trabalho o caráter ambíguo de produzir o homem e, ao mesmo tempo, provocar sua destruição (TUMOLO, 2005).

Sob o modo de produção capitalista, a existência humana é subjugada aos fins mercadológicos e o trabalho, organizado para atender as demandas do processo produtivo, encontra-se em níveis de exploração cada vez mais severos. 
Assim, a expropriação dos bens materiais é acompanhada da alienação da riqueza intelectual. Sob as condições do capitalismo, o legado histórico que compõe os saberes formais, obtido pelo conjunto dos homens, é negado a uma maioria da população que constitui a classe trabalhadora. Ou seja, as relações que definem materialmente a vida, interferem também na formação da consciência humana, excluindo a maioria das pessoas das condições de desenvolvimento humano obtidas coletivamente.

Saviani (2007), ao discutir a interferência da economia sobre as ideias pedagógicas no Brasil, nos apresenta questões relevantes para compreendermos as relações entre os problemas educacionais e a esfera produtiva. Dentre outras questões, o autor aborda a "pedagogia da exclusão" e explica que

A ordem econômica atual, pós-fordista e pós-keynesiana, pressupõe, ou melhor, assenta-se na exclusão, categoria que comparece duplamente: ela é pressuposta, num primeiro sentido, na medida em que se admite, preliminarmente, que na ordem econômica atual não há lugar para todos. Portanto, boa parte daqueles que atingem a idade para ingressar na População Economicamente Ativa (PEA) nela nem sequer chega a entrar. Num segundo sentido, a exclusão é pressuposta porque, incorporando crescentemente a automação no processo produtivo, a ordem econômica atual dispensa, também de forma crescente, mão de obra. Estimulando a competição e buscando maximizar a produtividade, isto é, o incremento do lucro, a extração de mais-valia, ela rege-se por uma lógica que estabelece o predomínio do trabalho morto (capital) sobre o trabalho vivo, conduzindo à exclusão deliberada de trabalhadores (SAVIANI, 2007, p.428).

Constata-se que a exclusão é, portanto, resultado da forma como as relações de trabalho estão organizadas. Pois, desde a introdução da maquinaria, esta não teve o significado de atenuar o sofrimento do trabalhador, ao contrário, tornou-se o meio para os capitalistas produzirem mais valia, que permite decrescer continuamente o valor da força de trabalho e ampliar o abismo entre as condições de vida do trabalhador e as do capitalista (MARX, 1984, p. 151).

Assim, o aperfeiçoamento do processo produtivo e a sofisticação dos instrumentos de produção, acompanhados da apropriação privada dos bens produzidos, colocam a classe trabalhadora numa condição que lhe confere submissão e condições de vida significativamente aviltantes, uma vez que dispensam o trabalhador dos postos de trabalho, bem como lhe reservam uma formação superficial. De acordo com Saviani (2007), nesse novo contexto

[...] é o indivíduo que terá de exercer sua capacidade de escolha visando adquirir os meios que lhe permitam ser competitivos no mercado de trabalho. E o que ele pode esperar das oportunidades escolares já não é o acesso ao emprego, mas a conquista do status de empregabilidade. A educação passa a ser entendida como um investimento em capital humano individual que habilita as pessoas para a competição pelos empregos disponíveis. $\mathrm{O}$ acesso a diferentes graus de escolaridade amplia as condições de empregabilidade do indivíduo, o que, entretanto, não lhe garante emprego, pelo simples fato de que, na forma atual do desenvolvimento capitalista, não há emprego para todos: a economia pode crescer convivendo com altas taxas de desemprego e com grandes contingentes populacionais excluídos do processo (SAVIANI, p.428, grifos do autor). 
A grande massa trabalhadora, submetida às demandas da produção nesse patamar de alto desenvolvimento tecnológico e, principalmente, sob as contradições do capitalismo, tem sua necessidade de conhecimentos para as atividades laborais bastante reduzida. Pois, "essas mudanças na organização do trabalho e dos instrumentos significam a difusão de uma nova racionalidade e padrão de individualidade que prescindem da atividade reflexiva, da experiência fundada na compreensão" (GALUCH; PALANGANA, 2008, p. 79).

Assim como ocorre a redução dos postos de emprego, a maioria deles requer o desenvolvimento de habilidades mentais mínimas. Essa situação repercute na educação tendo como consequência o declínio da exigência de concisão teórica e de rigor conceitual na seleção de conteúdos que vão compor a organização curricular das escolas. Nesse sentido, os conceitos científicos tornam-se desnecessários para as práticas laborais, pois estas exigem apenas procedimentos possíveis na esfera dos conceitos adquiridos pela experiência imediata.

No entanto, Moraes (2003) esclarece que no atual estágio de desenvolvimento das forças produtivas sob a organização capitalista, esse declínio na formação não se estende a todos os sujeitos, e completaríamos, nem a todos os países:

Para alguns, exigem-se níveis crescentemente altos de aprendizagem, situados em um domínio teórico-metodológico que a experiência empírica, por si só, é incapaz de garantir. Para a maioria, porém bastam as competências no sentido genérico que o termo adquiriu nos últimos tempos, as quais permitem a sobrevivência nas franjas de um mercado de trabalho com exigências diferenciadas e níveis de exclusão jamais vistos na história (MORAES, 2003, p.152).

Portanto, a formação pretendida para a maioria das pessoas atende às expectativas hegemônicas e à necessidade de uma formação unilateral para o trabalhador, adequando-o às exigências do processo produtivo sob a égide do capitalismo contemporâneo. Lembramos que a formação do homem para o trabalho, sob as relações mais atualizadas de produção, "tem tudo a ver com os objetivos da sociedade. Esses objetivos não coincidem com a ampliação da humanidade e espiritualidade do trabalhador, antes as anulam" (GALUCH; PALANGANA, 2008, p. 78).

Evidenciamos que a preparação restrita para o atendimento das demandas produtivas se opõe à formação para a humanização, pois esta possibilitaria ao homem o desenvolvimento máximo de suas capacidades intelectuais, enquanto aquela se ocupa tão somente do desenvolvimento de ferramentais intelectuais mínimas que permitam o controle ideológico e o desempenho das atividades laborais.

Nesse sentido, destacamos que as formulações de Vigotski acerca dos conceitos científicos e das possibilidades de uma relação consciente com a realidade implicam, diante da materialidade que nos está posta, o reconhecimento das contradições que definem e limitam a formação humana.

\section{Considerações finais}

Consideramos que, por meio da apropriação dos conceitos científicos, a criança supera a imediaticidade e a redução que predominam na relação direta com os objetos e obtém a capacidade de compreensão que é promovida pelas relações mediadas. Assim, os vínculos com a experiência são ultrapassados pelas elaborações abstratas.

Portanto, os conceitos científicos proporcionam para o sujeito inteligibilidade acerca 
da realidade. $\mathrm{O}$ cotidiano, determinado pelas concreticidades das relações sociais, não se torna nítido ao sujeito que dispõe apenas dos conceitos espontâneos para suas elaborações mentais. Pois, não é pela aparência dos fenômenos que podemos explicá-lo, mas pela busca da essência, e esta exige a apropriação das formas mais desenvolvidas de elaboração humana.

Ao compreendermos o trabalho como elemento fundante do ser social, entendemos que os limites postos para a formação humana na atualidade têm sua base nas relações de trabalho. A questão indica, portanto, que a precariedade presente nos processos educacionais está relacionada com as contradições advindas da esfera produtiva que atualmente determinam a desvalorização do conhecimento e fornecem obstáculos para obter a elevação da consciência humana aos patamares mais elevados de apropriação conceitual.

Igualmente, entendemos que a busca pelo desenvolvimento dos conceitos científicos exige mediações adequadas. Situa-se nesse aspecto um dos desafios da escola contemporânea que, como processo de educação formal, necessita de procedimentos adequadamente pensados para a consolidação de sua função. Cumpre-nos destacar ainda que a opção por formas educacionais que operem a formação dos conceitos científicos implica a preferência por uma perspectiva de sociedade que se projeta para uma formação humana mais ampla, o que exige considerar a necessidade de transformação das relações que nos estão postas na vigente organização social.

\section{Referências:}

GALUCH, M. T. B.; PALANGANA, I. C. Experiências, cultura e formação no contexto das relações de produção capitalistas. Intermeio (UFMS), V.15, p. 71-87, 2008.

LEONTIEV, A. O desenvolvimento do psiquismo. Lisboa: Livros Horizonte, 1978.

MARX, K. A maquinaria e a indústria moderna. In: O Capital. São Paulo: Difel, 1984, Livro I, Cap. XIII, p. 7- 181.

MEKSENAS, P. As Noções de Concreto e Abstrato: suas relações com a prática de ensino. Faculdade de Educação. São Paulo; Vol. 18, n.1, (p.92-98),1992.

MORAES, M. C. M. Recuo da teoria. In: MORAES, Maria Célia M. de et al. Iluminismo às avessas: produção de conhecimento e políticas de formação docente. Rio de Janeiro: DP\&A, 2003.

SAVIANI, D. O neopositivismo e suas variantes: neo-escolanovismo, neoconstrutivismo, neotecnicismo (1991-2001). In.: SAVIANI, D. História das Ideias Pedagógicas no Brasil. Campinas, SP: Autores Associados, 2007.

TUMOLO, P. S. O Trabalho na Forma Social do Capital e o Trabalho como Princípio Educativo: Uma Articulação Possível? Educação e Sociedade, Campinas, vol. 26, n. 90, p. 239-265, Jan./Abr. 2005.

VIGOTSKI, L. S. O Desenvolvimento dos Conceitos Científicos na Infância. In: $A$ Construção do Pensamento e da Linguagem. Martins Fontes, 2009, 241-394.

VIGOTSKI, L. S. Psicologia pedagógica. $3^{\mathrm{a}}$ ed. - São Paulo: Editora WMF Martins Fones, 
2010.

VIGOTSKI, L. S. Pensamento e linguagem. São Paulo: Martins Fontes, 1991.

VIGOTSKI, L. S. Obras Completas: fundamentos de defectologia. Tomo V. Cuidad de Habana: Editora Pueblo y Educación, 1989.

\footnotetext{
${ }^{1}$ Professora do Instituto Federal do Paraná-Campus Ivaiporã. Mestre em Educação pelo Programa de PósGraduação da Universidade Estadual do Oeste do Paraná (UNIOESTE). Doutoranda em Educação pelo Programa de Pós-Graduação da Universidade Estadual de Maringá (UEM). Membro do Grupo de Pesquisa Desenvolvimento, Aprendizagem e Educação. E-mail: elianebrunetto@gmail.com

2 Professora Associada do Programa de Pós-graduação em Educação, Universidade Estadual de Maringá (UEM). Doutora em Psicologia Escolar e do Desenvolvimento Humano pela Universidade de São Paulo e PósDoutora pela Universidade Federal de São Carlos.Líder do Grupo de Pesquisa Desenvolvimento, Aprendizagem e Educação. E-mail: nnrmori@uem.br
}

Recebido: Março/2016. Aprovado: Abril/2017. 